\title{
A NORMATIVIDADE DO DIREITO REAL DE LAJE NO BRASIL ENTRE OS PARADIGMAS DE DIREITO CIVIL CONSTITUCIONAL E DE SOCIEDADE DE DIREITO PRIVADO
}

\author{
Francisco Cardozo Oliveira ${ }^{1}$ \\ Guilherme Carta Ribeiro
}

\section{Resumo}

$\mathrm{O}$ artigo trata da normatividade do direito real de laje no direito brasileiro, em face dos paradigmas de direito civil constitucional e de sociedade de direito privado. A premissa de que o direito real de laje está comprometido com a inclusão social, mediante a titularização proprietária de modos informais de autoconstrução, em áreas ocupadas pela população carente, é confrontada com os processos de financeirização implicados no mercado imobiliário. O objetivo é analisar o quanto a introdução do direito real de laje no Código Civil pode constituir evidência de uma transição de fundamentos no direito civil.

Palavras-chave: direito real de laje; direito de propriedade; direito imobiliário; construção; fundamentos do direito civil;

\section{THE NORMATIVITY OF REAL SLAB RIGHT IN BRAZIL AMONG PARADIGMS OF CONSTITUTIONAL CIVIL LAW AND PRIVATE LAW SOCIETY}

\begin{abstract}
The article deals with the normativity of the real slab right in Brazilian law, in the face of the paradigms of constitutional civil law and private law society. The premise that the real slab right is committed to social inclusion, through the proprietary securitization of informal selfconstruction modes, in areas occupied by the needy population, is confronted with the financialization processes involved in the real estate market. The objective is to analyze how the introduction of the real slab right in the Civil Code can be evidence of a transition of fundamentals in civil law.
\end{abstract}

Key words: real slab right; property right; real estate law; construction; fundamentals of civil law;

\section{Introdução}

\footnotetext{
${ }^{1}$ Doutor em direito pela UFPR, estágio pós-doutoral na UFSC, Professor do PPGD do UNICURITIBA, Juiz de Direito no Tribunal de Justiça do Paraná. E-mail: xikocardozo@msn.com.

${ }^{2}$ Mestrando em direito no UNICURITIBA, pós-graduação em direito imobiliário pela Universidade Positivo, MBA em gestão imobiliária pela FGV, advogado. E-mail: guilherme.carta@ hotmail.com.
} 
A Lei n. $.^{\circ} 13465 / 2017$ introduziu no ordenamento jurídico brasileiro o direito real de laje, que promoveu a adição do inc. VIII ao art. 1245 e dos artigos 1510-A e seguintes ao Código Civil. O direito real de laje deve regular os casos de construções sobre a edificação do teto da moradia constituído por uma estrutura de laje de concreto armado, capaz de suportar sobre sua superfície uma outra área construída; invariavelmente, a estrutura da laje, decorrente de processos de autoconstrução, permanece inacabada, como estágio da construção da moradia, que não pode ser concluída com a edificação da cobertura. O direito real de laje, de forma mais específica, está destinado a tutelar direitos de pessoas residentes em locais de favelas, ou em áreas ocupadas pela população de baixa renda; trata-se de direito que, a princípio, não terá utilização ampla no mercado de construção civil de imóveis para as classes médias e alta; a menos que esse mercado consiga elaborar novos produtos no mercado ampliando o conteúdo do direito real de laje.

A regulação do direito real de laje está atrelada à política de titularização proprietária que, ao mesmo tempo em que regulariza a propriedade da estrutura, propicia mercado para a apropriação proprietária da parte superior da laje. A titularização proprietária da superfície da laje, no atual contexto socioeconômico brasileiro, suscita reflexão acerca dos contornos do alcance jurídico do direito real de laje. Para essa tarefa, revela-se importante confrontar dois paradigmas que buscam conferir sentido aos institutos de direito privado, o que exigirá uma reconstrução histórica, também desdobrada em dois níveis, um jurídico e outro econômico e político. O primeiro deles pode ser identificado com os pressupostos do direito civil constitucional que, no Brasil, tem servido para objetivar uma normatividade comprometida com valores existenciais da pessoa, desde o texto da Constituição. O segundo, resumido na premissa de sociedade de direito privado, identifica-se com a tutela da concorrência na Constituição, nos termos de uma ordem econômica constitucional, e o modo como ela influencia a dinâmica dos direitos, em especial o direito à moradia, quando visto como meio para a viabilidade dos mercados de crédito.

Desse confronto de paradigmas emerge o problema da análise: investigar o alcance da normatividade do direito real de laje considerado, de um lado, a tutela existencial da pessoa e, de outro, a tutela de interesses mercantis, na perspectiva da ordem econômica constitucional.

Colocam-se dois objetivos para a investigação: o relacionado à viabilidade dos pressupostos do direito civil constitucional, em face das dinâmicas da governabilidade 
neoliberal, na atualidade brasileira; e o que diz respeito aos escopos da tutela do direito real de laje no interesse da pessoa humana, levando em conta, neste caso, que esse direito real vai atingir interesses individuais e sociais de pessoas de baixa renda.

Para enfrentar o problema proposto, o texto se desdobra desde a análise da relação entre os pressupostos da constitucionalização do direito civil e a tutela dos direitos existenciais, passando pela compreensão do contexto socioeconômico de regulação do instituto do direito a moradia e do direito de laje, até alcançar a questão do papel do direito de laje na proteção da pessoa, em confronto com a financeirização do mercado imobiliário.

Utiliza-se um método dialético e crítico, que adquire contornos na medida em que se desenvolve a reflexão; a pesquisa se apoia em material bibliográfico.

\section{Direito civil constitucional e a tutela dos direitos existenciais}

As premissas do direito civil constitucional introduziram uma tensão na dogmática do direito civil, na medida em que tornaram explícitas as limitações da codificação, e seu corolário de completude, na tutela de titularidades e direitos na vida em sociedade. O direito civil constitucional busca operar a efetividade das normas constitucionais no âmbito das relações de direito privado. Essa operatividade pode ser mais bem compreendida mediante um recorte interdisciplinar, desde uma postura metodológica reconstrutiva, que seja capaz de evidenciar o caráter existencial e fenomenológico da titularidade e do exercício de direitos de moradia levando em conta, para o que interessa para análise de modo específico, a realidade social e econômica brasileira.

\subsection{Reconstrução normativa dos fundamentos do direito civil constitucional}

A metodologia de reconstrução observa uma lógica identificada na filosofia hegeliana, que teria considerado a necessidade de aderência histórica da evolução da vida em sociedade, e de mensuração dos efeitos das ideias e dos propósitos dos projetos de construção da socialidade. Especialmente em relação ao direito, o método reconstrutivo surge esboçado 
na Filosofia do Direito quando Hegel afirma que "o estudo da origem e desenvolvimento das regras jurídicas tais como aparecem no tempo, trabalho puramente histórico, bem como a descoberta da sua coerência lógica formal com a situação jurídica já existente constituem investigações que, no seu domínio próprio, não deixam de ter valor e interesse” (2003, p. 56).

Embora se mostre, desde logo, a necessidade de ter em conta a separação entre o simples relato histórico dos institutos jurídicos e o conceito deles propriamente dito, o que está em causa é exatamente pensar o conceito jurídico na dimensão da sua historicidade, porque é somente nesse nível que se revela a racionalidade e a justiça da norma. Em termos de reconstrução normativa, que tenha como relevante os fundamentos do ordenamento jurídico, importa apreender o alcance e a limitação dos institutos jurídicos em um determinado tempo histórico.

Observada a premissa metodológica de reconstrução normativa, o paradigma do direito civil constitucional buscou estabelecer a possibilidade de a norma constitucional incidir sobre o conteúdo das relações de direito civil; nesse sentido, Pietro Perlingieri afirmava que não se trata de considerar a norma constitucional como mera regra hermenêutica, mas como norma de comportamento que incide na relação de direito civil, de modo a que os valores constitucionais possam assegurar possibilidades de funcionalização nas situações subjetivas. Trata-se, diz ele, de harmonizar o direito civil e os direitos fundamentais, de acordo com as necessidades existenciais das pessoas (2009, p. 590-591).

Em torno do direito civil constitucional, portanto, gravitam valores de interligação entre o direito civil e os direitos fundamentais, que exigem uma hermenêutica comprometida com a perspectiva existencial da pessoa e com seu projeto de vida.

A repercussão dessas premissas no Brasil aproveitou-se da entrada em vigor da Constituição de 1988 para afirmar a necessidade de conferir novos pressupostos aos fundamentos do direito civil. Nessa linha, Luiz Edson Fachin sustenta que o direito civil constitucional rompe a dicotomia tradicional entre direito público e direito privado, ao introduzir na Constituição transformações fundamentais no direito de propriedade, que surge vinculado à função social, no direito de família, em que o plano interno da família pressupõe relações igualitárias, e nas relações contratuais, na preocupação com os direitos do consumidor e com a justiça distributiva (2000, p. 10-11). O paradigma de direito civil 
constitucional representaria um momento de mutação nos fundamentos do direito privado, cujo ponto de partida, do ponto de vista legislativo, seria a Constituição de 1988.

A constitucionalização do direito civil, contudo, não foi recepcionada sem resistências. Paulo Lobo lembra o desencanto de Natalino Irti com a instabilidade em torno da relação entre direito civil e Constituição; ele teria passado a defender uma recodificação do direito privado em face das mudanças sociais e históricas. Paulo Lobo lembra ainda que, no Brasil, o Código Civil de 2002 teria representado, para parte dos tradicionalistas, um retorno do direito civil ao codificado; mas ele adverte, em defesa da constitucionalização, que a aplicação das regras do Código Civil exige cuidado para assegurar o vigor do núcleo normativo da Constituição sobre o direito civil (2013, p. 55).

Mais recentemente, começou a ganhar evidência a crítica aos fundamentos da constitucionalização do direito civil; Fernando Leal crítica a instrumentalização dos institutos de direito civil para atingir finalidades, com as consequências decisionistas e seus corolários de ceticismo em relação a regras (2015, p. 123-165). Nessa linha crítica, Otávio Luiz Rodrigues $\mathrm{Jr}$ afirma que a aplicação de princípios constitucionais conduz ao risco de desprestigiar o direito legislado no Código Civil, em favor de uma retórica de potencialização da eficácia do texto constitucional; ele lembra a ideia de constitucionalização simbólica de Marcelo Neves e afirma que "na retórica de grupos interessados em transformações reais nas relações de poder, os quais pretendem frequentemente representar a "subcidadania" invocam-se os direitos proclamados no texto constitucional para renunciar a "realidade constitucional inconstitucional" e atribuir ao Estado/governo dos "sobrecidadãos" a culpa pela não realização generalizada" dos direitos previstos na Constituição (2019, p. 223).

A crítica formulada por Otávio Luiz Rodrigues Jr se amolda à questão do direito à moradia em que, de um lado, o mercado não consegue prover moradias a preços compatíveis com a renda e as necessidades das pessoas, notadamente as de baixa renda, enquanto que o Estado não tem sido capaz de formular política habitacional suficientemente eficaz para dar conta das necessidades de habitação da população.

Vista a questão nos dias atuais, na realidade brasileira, o percurso reconstrutivo mostra que o paradigma do direito civil constitucional, pelo menos no que diz respeito ao direito fundamental à moradia (art. 6. ${ }^{\circ}$ da Constituição), parece não ter sido capaz de contribuir para ampliar possibilidades de titularização, em face das desigualdades de renda e 
da forma como articulado o mercado imobiliário. Ainda que tenha aumentado a oferta de moradia, inúmeras pessoas continuam marginalizadas vivendo em locais precários no Brasil.

\subsection{0 caráter existencial do direito à moradia na realidade social brasileira}

A permanência das restrições de acesso ao direito à moradia, conforme evidenciado pela reconstrução normativa dos fundamentos do direito civil constitucional e, consequentemente, do direito fundamental à moradia, exige precisar o alcance do direito à moradia, de modo a situá-lo em termos de eficácia no contexto social e econômico brasileiro.

A titularização do direito à moradia tem correlação incontornável com a configuração do direito de propriedade imobiliária.

A coisa como própria, sujeita ao poder do proprietário, que está na base da premissa de domínio, e que caracterizaria o direito de propriedade ao longo da modernidade, contempla uma perspectiva individualista em que, de forma paradoxal, permitiu a coisificação da pessoa, na forma da escravidão e da objetificação, ao mesmo tempo em que o discurso de tutela da pessoa resulta dúbio, em face da proteção do que é mais específico do humano, que é o corpo.

A construção do fundamento do direito de propriedade em torno do domínio sujeita a coisa à pessoa; a propriedade consistiria no domínio da pessoa sobre a coisa, conforme, inclusive, preconiza a teoria realista na explicação dos direitos reais, que coloca ênfase nos interesses do titular do direito e reforça a prevalência dos interesses individuais, no quadro da economia liberal.

Por outro lado, a premissa de uma razão que se sobrepõe ao corpo, na esteira do pensamento de Descartes e de Hobbes, favorece a ideia de que o direito de propriedade pressupõe a sujeição da coisa à vontade do proprietário.

Contudo, Spinoza afirma a importância do corpo, que é afetado por outros corpos; ele elabora a premissa de natureza em que o homem é corpo e mente; e, mais, que o homem se constitui por vários corpos que são afetados; para além da razão, os afetos também compõem a essência do ser humano; em face da existência do corpo, as coisas também integram a natureza mas, segundo Spinoza, não em face da contingência, mas da necessidade (2015, p. 51-94). Logo, tomada a apropriação que compõe o direito de propriedade, não se 
trata do domínio da pessoa sobre as coisas, mas do modo como o corpo interage com as coisas, em razão das necessidades.

$\mathrm{Na}$ medida em que o corpo também é afetado pelas coisas, não se trata exclusivamente de um direito de propriedade que possa estar apoiado no domínio da pessoa sobre a coisa; trata-se do modo como a interação da pessoa com a coisa (o corpo afetado pela coisa) pode ser protegida pelo direito de propriedade, de modo a atender as necessidades da vida em sociedade; evidencia-se nessa interação o caráter existencial do direito de propriedade na medida em que, como lembra Stefano Rodotà, a tutela jurídica da liberdade da pessoa pode depender da extensão do comportamento possibilitado pela posse de coisas (a bolsa, a mala, o automóvel). Consequentemente, seguindo o que diz Stefano Rodotà, a vida não pode ser definida apenas pela qualidade da pessoa de dono (proprietário); é necessário que o direito contemple modos de tutela da pessoa que não se restrinjam a forma de apropriação da propriedade, principalmente quando está em causa a preservação da saúde, do conhecimento e do acesso à informação (2012, p. 81 e 134).

$\mathrm{O}$ direito à moradia, na medida em que assimila a garantia de direito social fundamental na Constituição brasileira de 1988 (art. 6. ${ }^{a}$ ), está informado pelo conteúdo existencial do direito de propriedade. Trata-se do modo como a moradia afeta o corpo, e consequentemente a vida da pessoa em sociedade.

$\mathrm{O}$ direito fundamental à moradia, dado o caráter existencial que encerra, não se esgota no modelo de apropriação característico do direito de propriedade, mediado pelo mercado. No direito à moradia se configura uma espécie de situação subjetiva patrimonial complexa, no sentido do formulado por Pietro Perlingieri (1999, p. 224), em que a apropriação da coisa, no caso a moradia, confere sentido a existência da pessoa em um determinado contexto social. Trata-se do que o próprio Pietro Perlingieri define como interesses existenciais da pessoa merecedores de tutela (1999, p. 230).

O Código Civil quando trata do direito de propriedade, no artigo 1228, não chega a especificar o caráter existencial do direito à moradia, embora disponha no $\S 11^{\circ}$ acerca dos deveres a serem observados pelo titular no exercício dos poderes proprietários. No âmbito dos estatutos de direito privado, é o Estatuto da Cidade que especifica o alcance do direito à moradia (art. 2. ${ }^{\circ}$ ) na medida em que regula o uso do solo urbano nas cidades. Mas o Estatuto da Cidade não chega a diferenciar a tutela específica de um direito à moradia, dotado de obrigação própria e de sua consequente exigibilidade em face do Estado e da sociedade; nos 
estatutos de direito privado, o direito à moradia permanece atrelado ao desenho de políticas urbanísticas e sociais capazes de favorecer a construção de habitações intermediada pelo mercado; nesse sentido, o direito à moradia continua carente de eficácia e efetividade dado que, no nível pragmático, a ordem jurídica brasileira não assimilou o caráter existencial da moradia e sua relação com a preservação da pessoa.

\section{Sociedade de direito privado e a tutela da concorrência na Constituição}

Ficou evidenciado que o paradigma do direito civil constitucional, tomado a história de vigência da Constituição brasileira de 1988, parece não ter sido capaz de propiciar tutela efetiva ao direito à moradia; de um lado, a realidade socioeconômica mostra que não tem sido construídas habitações suficientes no Brasil para atendimento das necessidades da população; de outro lado, o próprio ordenamento jurídico parece não estar comprometido com uma obrigação específica, inerente ao caráter existencial do direito à moradia, capaz de assegurar-lhe eficácia e efetividade.

O impasse identificado exige examinar o arcabouço de sentido do modelo econômico tutelado pela Constituição de 1988, dado que o caráter prestacional do direito à moradia implica a alocação de recursos materiais e humanos. O exame dessa questão deve levar em conta a relação do modelo econômico com a tutela do direito à moradia e dos interesses existenciais da pessoa, o que implica elaborar uma reconstrução histórica dos fundamentos da governabilidade neoliberal, de modo a situá-la no contexto da ordem econômica constitucional para, na sequência, analisar a repercussão no alcance do acesso à habitação.

\subsection{Reconstrução histórica dos fundamentos da governabilidade neoliberal e o acesso a habitação}

O paradigma reconstrutivo nesse momento assume feição histórica. Trata-se de analisar o contexto social e econômico que demanda a efetividade do direito à moradia no Brasil. Está pressuposto na análise reconstrutiva a verificação do quanto avançaram na 
realidade brasileira as condições sociais e econômicas, capazes de assegurar acesso à moradia e, consequentemente, seus reflexos no direito de laje.

A governabilidade neoliberal, conforme enfatiza Michel Foucault, está apoiada na institucionalização social, econômica e jurídica, da concorrência, por oposição a formas de intervencionismo do Estado na economia, grosso modo no estilo das políticas keynesianas adotadas em meio a 2. a Guerra Mundial e depois da crise de 1929, principalmente nos Estados Unidos. A estruturação da concorrência nos mercados, pensada pela racionalidade econômica neoliberal, exige considerar o modo como a produção, desde o trabalho, está concebida sob a forma da atividade-empresa. O trabalhador, por exemplo, não é o detentor da força de trabalho explorada no mercado de trabalho como proposto por Marx, mas pessoa dotada de competências que lhe permite ingressar e permanecer nos fluxos de renda ao longo da vida. Como diz Michel Foucault se referindo a vertente do neoliberalismo americano "Não é uma concepção de força de trabalho, é uma concepção do capital-competência, que recebe, em função de variáveis diversas, certa renda que é um salário, uma renda-salário, de sorte que é o próprio trabalhador que aparece como uma espécie de empresa para si mesmo" (2008, p. 310).

Segundo a racionalidade social e econômica neoliberal, a pessoa é o empresário de si mesmo; a lógica da concorrência atinge o modo como construída a subjetividade, no contexto da vida social e econômica. O sucesso ou o fracasso da pessoa não dependeria mais da articulação de esferas de proteção social, mas do modo como ela própria articula suas competências e seus talentos para explorar possibilidades de fluxos de rendas surgidas nos mercados, ora como sujeito consumidor, ora como produtor de mercadorias. A premissa da pessoa que se articula mediante empresário de sí mesmo incorpora também as necessidades do sujeito consumidor no mercado de bens e serviços. A racionalidade econômica neoliberal, dessa forma, estrutura os elementos que fundamentam a consolidação da sociedade de consumo de massa.

Estabelecer a concorrência e a forma empresa como elementos estruturantes da vida social, exige considerar o modo como se torna possível destacar na natureza os elementos capazes de conferir dinamismo econômico aos mercados. Para a racionalidade neoliberal é necessário submeter os vários domínios da vida a uma análise econômica que tenha como relevante indicar uma utilidade empresarial e lucrativa, do que não escapa, inclusive, o campo jurídico, mediante as variadas abordagens da chamada análise econômica 
do direito. A empresarialidade da vida implica, em última análise, a submissão da natureza à forma da propriedade privada, com os riscos decorrentes para o meio ambiente e para a existência humana.

Na perspectiva do direito, a racionalidade econômica neoliberal não se limita a exigência de submissão do campo jurídico à uma análise econômica, em termos de possibilidades de vantagens empresariais; impõe-se reorientar os próprios fundamentos da racionalidade jurídica.

Nesse sentido, Friedrich Hayek formula a ideia de uma sociedade de direito privado (Privatrechtsgesellshaft), regida pela ordem espontânea do mercado. Trata-se de tomar as regras de conduta justa não apenas no sentido de regulação de fins particulares, mas de toda a ordenação da vida social; de acordo com Friedrich Hayek, "Isso significa que, conquanto essas normas sirvam, em última instância, a fins particulares (embora em sua maioria desconhecidos), elas só os servirão se forem tratadas não como meios, mas como valores últimos, na verdade como os únicos valores comuns a todos e distintos dos fins particulares dos indivíduos" (1985, p. 17-18).

$\mathrm{Na}$ visão de Friedrich Hayek, são as regras de conduta, e consequentemente o direito privado, que conferem organicidade a vida social e econômica; antes mesmo da positividade da lei no ordenamento jurídico, as regras e costumes regem as práticas comerciais, de modo que são as regras das práticas mercantis, compreendidas no direito privado, que constituem o fundamento da ordem jurídica neoliberal: um direito baseado no costume e na tradição. Para Hayek são as regras de direito privado que devem reger, inclusive, o Estado; ele reduz o sentido de Estado de Direito a absorção das regras de direito privado, o que o aproxima da formulação de Carl Schmitt de um Estado capaz de assegurar a autonomia dos mercados e evitar interferência política na administração da economia (2007).

O que está em jogo na formulação de Hayek, segundo Pierre Dardot e Christian Laval, é a preservação da eficiência da ordem do mercado, em que o papel do Estado é o de atuar apenas de forma coercitiva para punir as infrações das regras de conduta e garantir a segurança dos agentes econômicos; o Estado se reduz, praticamente, ao monopólio da força e à coerção na forma de impostos, necessários ao desenvolvimento dessas atividades de manutenção da ordem liberal e do mercado (2016, p. 178-179).

No contexto de regência da vida social, e na perspectiva de um Estado de Direito reduzido às normas de direito privado, não tem lugar uma política pública de habitação. $\mathrm{O}$ 
acesso à moradia passa a depender exclusivamente das competências e das rendas auferidas pelo indivíduo. Contudo, levando em consideração a realidade brasileira, em termos de reconstrução histórica, as evidências empíricas conduzem a conclusão de que o mercado não tem sido capaz de prover necessidades de moradias, e nem ao menos de renda suficiente que permita ampliar o acesso do indivíduo ao mercado imobiliário, em especial para as pessoas de baixa renda.

Em termos de reconstrução histórica, para o que interessa especificamente para a analise proposta, o quanto tenha avançado a concepção de Estado de Direito reduzido às normas de direito privado no Brasil, com a consequente erosão das premissas de constitucionalização do direito civil, somente pode ser objetivamente avaliado à luz do alcance da normatividade do direito à moradia e do direito de laje.

\subsection{Morar e viver mediado pela concorrência no contexto das cidades brasileiras}

$\mathrm{Na}$ atualidade, a efetividade do direito à moradia, no Brasil como em outros países, está sujeito à lógica da concorrência e da financeirização da economia globalizada. A atual crise da economia capitalista, que se iniciou em 2008, tem como um dos eixos centrais o financiamento imobiliário e suas repercussões nos mercados de crédito. Trata-se de inserir o mercado imobiliário na lógica do que François Chesnais qualifica de capital portador de juros (2016).

$\mathrm{Na}$ Espanha, por exemplo, que foi um dos países atingidos pela crise econômica de 2008, intensificou-se o debate em torno do direito à moradia digna, com repercussão da legislação reguladora da matéria.

A crise financeira se materializou na Espanha quando o fluxo de capital convergiu para o mercado imobiliário em busca de maiores ganhos, mas as possibilidades de retorno se revelaram ilusórias; na sequência, ocorreu a redução drástica de crédito, em meio à desvalorização de imóveis e a manutenção de dívidas sem possibilidade de pagamento pelos tomadores de empréstimos destinados a aquisição da moradia.

No plano jurídico, em 2013, por causa da crise econômica, a Espanha modificou a disciplina legal da execução hipotecária. A Lei n..$^{\circ}$ 1/2013, de 14 de maio, buscou reforçar a 
proteção dos devedores hipotecários, permitir a reestruturação de dívidas e regular o aluguel social. A nova lei suspendeu os despejos pelo prazo de dois anos, de modo a proteger pessoas e famílias vulneráveis; essa lei resultou da sentença de 14 de março de 2013, do Tribunal de Justiça da União Europeia, que reconheceu a vulnerabilidade do devedor na execução hipotecária no ordenamento jurídico espanhol.

A crise de 2008 despertou na Espanha a importância do direito à habitação digna, confrontado com o modelo de acesso baseado na financeirização proprietária da moradia, com seu pressuposto concorrencial do território das cidades, reduzido a ativo urbano e visto pelo mercado como oportunidades de consumo. Conforme afirmam Raquel Rodriguez Alonso e Mario Espinoza Pino, na base do modelo de financeirização do acesso à moradia, está a premissa de reduzir a habitação a mercadoria, deixando em segundo plano a ideia de bem necessário a sobrevivência da pessoa, de modo a ampliar a especulação imobiliária a todos os lugares capazes de sustentar capacidades de endividamento; eles afirmam que estão em curso na Espanha estratégias sociais, políticas e jurídicas para recuperar o caráter da moradia como necessidade vital (2017, p. 25 e 108).

A referência ao caso da Espanha serve para evidenciar os riscos e limites envolvidos na financeirização do acesso a moradia, mediada pela inserção do território das cidades na dinâmica de concorrência do mercado.

No Brasil, a crise de 2008 retardou seus efeitos que só se manifestaram com mais intensidade a partir de 2012. Assim, embora tenha havido crise, não chegou a se consolidar no Brasil uma crise de moradias, com a multiplicação de despejos, ou de execuções, como ocorreu na Espanha, possivelmente porque no caso brasileiro, é restrito o mercado de habitação com financiamento privado, voltado para as pessoas de baixa renda. Embora o território das cidades esteja sujeito à lógica da concorrência, o mercado imobiliário no Brasil encontra dificuldades de expansão, em função das limitações de renda da maior parte da população.

No caso brasileiro, o mercado imobiliário, ao longo da história, esteve atrelado, por um lado, às políticas públicas de habitação para famílias carentes e limitado, por outro, pela prática da autoconstrução de moradias.

Nesse sentido, caberia destacar o modo como a financeirização alcança o direito à moradia no Brasil e a prática da autoconstrução, considerando-se, neste último caso, a relação direta com o direito de laje. 
Em relação à financeirização, é interessante observar o que ressalta Raquel Rolnik, no que diz respeito a especificidade da articulação entre agentes do mercado imobiliário e as políticas públicas de habitação, cujos efeitos, em termos de ampliação de direitos, emerge mediado pela satisfação de interesses financeiros e empresariais. Referindo-se ao programa Minha Casa Minha Vida - MCMV, que traduziu a política pública recente de construção de moradias no Brasil, Raquel Rolnik destaca o caráter ambivalente da iniciativa, na medida em que, ao mesmo tempo em que mobilizou recursos públicos para subsidiar a aquisição de moradia por pessoas de baixa renda, serviu para manter lucros no mercado da construção civil reproduzindo os padrões históricos de apropriação de fundos públicos por empresas privadas (2015, p. 309).

A financeirização da produção de moradias no Brasil se insere na lógica que marca o capitalismo brasileiro, em que o Estado tem o papel de assegurar a rentabilidade de investimentos privados, com resultado duvidoso na garantia do direito à moradia, o que, em última análise, está em consonância com o ideário do neoliberalismo.

O fenômeno da autoconstrução também tem longa trajetória na construção de moradias no Brasil. A ausência de políticas públicas de habitação e as limitações na obtenção de renda obrigam as pessoas a prover os meios para construir por conta própria a sua habitação. A paisagem da periferia das grandes cidades brasileiras está marcada pelo fenômeno da autoconstrução. A pessoa vai construindo sua habitação ao longo da vida e das possibilidades de renda; segundo Pedro Fiori Arantes, a autoconstrução está fora do mercado, pois a habitação é feita para consumo próprio e que, segundo ele, configura um bem precário, na medida em que produzido com pouca técnica, resulta em ambiente insalubre, e se limita a assegurar a sobrevivência dos pobres (2002, p. 189-190); muitas dessas construções permanecem inacabadas na altura da laje de cobertura. São elas, de forma direita, que podem ser beneficiadas com o direito de laje.

A laje, desse modo, é produto da autoconstrução e dos limites do mercado imobiliário no Brasil, com seu corolário de financeirização e de domínio da concorrência; mas ao mesmo tempo, com a regulação jurídica, a laje pode ser o elemento a potencializar a financeirização, na medida em que propiciar oportunidades de financiamento para a aquisição de moradia e, com isso, viabilizar um novo ciclo de valorização do capital portador de juros. 


\section{O direito real de laje entre a proteção jurídica da pessoa e a ampliação do mercado de crédito}

O exame da normatividade do direito de laje, a esta altura, permite avaliar o alcance e os limites dos paradigmas do direito civil constitucional, na atualidade brasileira, confrontados com as premissas de sociedade do direito privado. Trata-se, portanto, de verificar o modo como a inserção do instituto do direito real de laje no direito civil brasileiro pode traduzir a encruzilhada em que se encontram os fundamentos do direito civil, e seus escopos de proteção da pessoa, em face do cenário de crise social e econômica que perdura no Brasil.

Convém examinar, de início, o modo como pode ser compreendido o sentido da normatividade do direito real de laje, à luz dos fundamentos do direito para, em seguida, traçar os reflexos da tutela do referido direito nos fundamentos do direito civil brasileiro.

\subsection{O alcance da normatividade do direito real de laje à luz dos fundamentos do direito}

Invariavelmente, a questão da normatividade na cultura jurídica brasileira, guardadas as devidas visões nuançadas, tem sido pensada através da dualidade entre jusnaturalismo e positivismo. Esse dualismo, inclusive, não é exclusivo da situação brasileira; antes, assinala uma oscilação que parece inscrita na tradição da modernidade e do direito moderno. Nesse sentido, Norberto Bobbio lembra que, na história jusfilosófica da Itália, a crise do direito derivada do excessivo legalismo, em meados do Século XX, resultou na "revolta contra o formalismo" e no ressurgimento de fundamentos jurídicos jusnaturalistas (2016, p. 35-40).

Um ponto comum que está implicado na dualidade que se estabeleceu ao longo da história da modernidade, entre jusnaturalismo e positivismo, é a visão idealista e abstrata do direito, que passa ao largo dos desdobramentos das formas de vida em sociedade. Enquanto o jusnaturalismo inscreve a normatividade na ordem da natureza, para dai derivar o direito positivo, o positivismo se apega ao caráter descritivo das normas jurídicas, de modo a sustentar o primado da neutralidade axiológica. Passando ao largo da convidativa hierarquização de méritos e deméritos do jusnaturalismo e do positivismo jurídico, é 
necessário reconhecer que o positivismo contribuiu de maneira decisiva para a consolidação do direito moderno, na medida em que a lei instaurou o pressuposto de igualdade formal e de direitos do homem e, com isso, contribuiu para superar a cultura de divisão social aristocrática do Medievo. Essa assertiva encontra apoio em Hegel que sustenta que o mundo moderno opera a passagem da moral para a eticidade em que, segundo ele, cabe ao Estado e à Constituição lutar contra as desigualdades ( 1982, p. 187). O sistema jurídico fundado na lei positiva, organiza a sociedade moderna; o que é mais importante, o sistema jurídico baseado na lei pressupõe a possibilidade de alterações exigidas pelo progresso. O desnível em relação ao Brasil é o de que tanto a igualdade formal como os direitos do homem, mesmo passado o Século XX, ainda carecem de solidez suficiente para superar desigualdades e assimetrias.

Tomando o sentido da separação entre ser e dever-ser, que está na base da teoria do direito de Hans Kelsen, pode ser o caso de pensar não a separação, mas o modo como o ser está imbricado com o dever-ser e vice-versa. Já na Filosofia do Direito Hegel sustenta que o que é racional é real e o que é real é racional, em defesa da historicidade e da necessidade de compreensão do conteúdo do comportamento tutelado pelo direito. Resulta fundamental, deste modo, compreender a normatividade do direito desde os desdobramentos da realidade social, e o modo como a regra integrante do ordenamento jurídico se revela capaz de assimilar tais desdobramentos. Trata-se, desse modo, de uma espécie de normatividade material, em que o alcance da regulação jurídica não se encerra no caráter abstrato da lei positiva.

A ideia de normatividade material se revela útil para a análise do direito real de laje, na medida em que permite compreender o alcance dos desdobramentos dos poderes $\mathrm{e}$ faculdades do titular, no contexto histórico da realidade brasileira, e de acordo com as características das formas da vida em sociedade.

\subsection{A tutela do direito real de laje e seus reflexos nos fundamentos do direito civil brasileiro}

O direito real de laje está regulado no Código Civil a partir do art. 1510-A. A introdução do direito real de laje no Código Civil veio no bojo da estrutura de regularização fundiária urbana e rural disciplinada pela Lei n. ${ }^{\circ}$ 13.465/2017. 
$\mathrm{Na}$ concepção do direito real de laje, a doutrina deu ênfase ao caráter social da possibilidade de construir sobre edificação alheia, em face da carência de moradias no Brasil, notadamente nas áreas de favelas. Nesse sentido, Cristiano Chaves de Farias, Martha El Debs e Wagner Inácio Dias afirmam que o direito real de laje viabiliza o direito à moradia e a regularização de milhares de edificações no Brasil (2018, p. 30). Arnaldo Rizzardo sustenta que o direito real de laje constitui arranjo para remediar a falta de moradias, buscando facilitar a socialização da propriedade habitacional nas grandes cidades e nas comunidades de extensa concentração de pessoa carentes com baixo pode aquisitivo, em vista da falta de espaço e do alto custo da propriedade imobiliária (2017, p. 263-275).

Partindo de uma visão institucionalista, Frederico Henrique Viegas de Lima sustenta que o direito real de laje, considerada a realidade social brasileira, introduz nova forma proprietária de modo a possibilitar o acesso a posições proprietárias, por parte das pessoas necessitadas de moradia; tratou-se, diz ele, de formalização do direito de propriedade em situação informal de habitações em áreas de escassez de espaço (2017, p. 251-280).

A discussão doutrinária sugere que o direito real de laje coloca em xeque o princípio do numerus clausus no direito das coisas e sua relação com o princípio da tipicidade. Paulo Lobo, mesmo antes da regulação legal do direito real de laje, argumentava com as limitações do princípio do numerus clausus afirmando que, "Costumes se impuseram, passando ao largo da lei, como o direito de laje (sobreelevação), em comunidades populares e o direito destacado de plantações (por exemplo, os coqueiros no litoral nordestino), antes da introdução do direito real de superfície." (2017, p. 39). Essa visão, de um direito real que emerge do costume encontra apoio em parte expressiva da doutrina brasileira. Seja como for, mesmo em torno do questionamento do princípio do numerus clausus, e da controversa premissa de uma configuração de direito real a partir do costume no ordenamento jurídico brasileiro, o que se evidencia na construção dos fundamentos do instituto é a defesa do caráter social do direito real de laje. O sentido desse caráter social do direito real de laje tende a favorecer uma perspectiva inclusiva em torno do direito reconhecido pelo ordenamento jurídico brasileiro.

A princípio, dado o caráter inclusivo, o direito real de laje estaria apoiado nas premissas do direito civil constitucional, que aposta no caráter existencial da situação jurídica de direito real. 
Ocorre que a constitucionalização do direito civil na realidade brasileira, conforme já afirmado, não teve força normativa suficiente para ampliar as titularidades de direitos de propriedade, no que diz respeito à efetividade do direito social fundamental à moradia.

Em face dessa dificuldade dos fundamentos de constitucionalização do direito civil, de ampliar o acesso à moradia ao longo das últimas décadas, sustentar a premissa de um caráter social do direito real de laje pode escamotear as finalidades que determinaram a introdução do instituto no ordenamento jurídico brasileiro, justo no momento em que o discurso de ampliação dos direitos sociais, no campo político, em decorrência da crise econômica, aprofundada a partir de 2015, perdia primazia em favor da racionalidade de preservação de ganhos nos mercados.

No atual cenário político, a regulação do direito real de laje ganha um sentido mais econômico do que social podendo estar em causa a formalização de titularidade proprietária para pessoas de baixa renda, de modo a criar oportunidades de dinamização do mercado imobiliário e do mercado de crédito, mediante formas de captura de rendas e de juros. Essa questão fica mais clara quando observado que, na Lei n. ${ }^{\circ}$ 13.465/2017, o direito real de laje se insere na estrutura de regularização fundiária urbana.

Conforme ressaltado por Daniela Rosário Rodrigues, observado o que constava do art. 46 da Lei n. ${ }^{\circ}$ 11977/2009, a regularização fundiária, na questão do acesso à moradia, incorpora uma premissa social de acesso ao direito de propriedade, no contexto das funções sociais da propriedade urbana (2013, p. 25-47). Contudo, a perspectiva social e de promoção da pessoa, que gravita em torno do instituto da regularização fundiária, parece ter ficado em segundo plano, com a edição da Lei n. ${ }^{\circ}$ 13465/2017, em que avulta o aspecto econômico da titularização proprietária no espaço urbano. Com efeito, conforme afirma Flávio Tartuce (2018, p. 1-23) na Lei n. ${ }^{\circ}$ 13465/2017 surge uma preocupação com a titularização de imóveis em situação de informalidade nas cidades, que está corroborado pelos objetivos elencados no art. 10 da referida lei, especificamente o que se refere ao propósito de organizar núcleos urbanos informais. Ainda que os aspectos sociais e de acesso à moradia estejam contemplados na Lei n. ${ }^{\circ}$ 13465/2017, a regulação fundiária carrega o propósito de multiplicação de titulação atrelado às finalidades econômicas do direito de propriedade privada. Assim, o propósito de política pública inerente à regularização fundiária, acaba reduzido em favor da prevalência de interesses econômicos. A regulação do direito real de laje, nesse contexto, se insere na lógica de premissa de sociedade regulada pelo direito privado. 
Mais se acentua a inserção do direito real de laje na lógica de sociedade regulada pelo direito privado quando observada a conexão direta entre o direito de propriedade imobiliária e a financeirização da economia neoliberal. A crise de 2008 evidenciou o papel que o mercado imobiliário joga na ampliação de ganhos com juros mediante a articulação de garantias hipotecárias e formas de securitização de recebíveis. A dinâmica de construção sobre lajes pode impulsionar o mercado de crédito, especialmente no Brasil em que, como lembram Mariana Fix e Leda Maria Paulani, os salários baixos não permitem acumular poupança (2019, p. 638-657), sem contar as possibilidades de ganhos propiciados pela redução da moradia a simples ativo financeiro.

A eficácia do direito não se resume a considerar a normatividade abstrata da lei, mas como já enfatizado pela doutrina, leva em conta os efeitos da norma na realidade social. Mas o alcance dos efeitos da norma na realidade social depende do modo como, em um determinado contexto social, se faz incidir a regra. A eficácia, portanto, está informada pelo modo como compreendida a norma e os fundamentos do ordenamento jurídico. Logo, é importante situar o escopo de sentido em que se dá a aplicação da norma em um determinado momento histórico, dado que é ele que determina o alcance do sentido normativo. Essa questão surge transfigurada no exame que Mariana Marques Auler faz da aplicação das regras do plano diretor de Curitiba, ao longo do tempo, entre variadas concepções políticas e de administração da cidade (2017).

A tutela do direito real de laje na lógica da premissa de sociedade de direito privado é indicativo de que os fundamentos do direito civil podem estar atravessando uma mudança de paradigma, em que o compromisso com a existencialidade da pessoa caminha para se tornar discurso vazio, confrontado com as exceções e urgências ditadas pela dinâmica dos mercados assimiladas pelo ordenamento jurídico e pelos tribunais.

\section{Considerações finais}


Colocou-se como problema de análise investigar o alcance da normatividade do direito real de laje, no contexto de confronto entre a tutela existencial da pessoa e a tutela de interesses mercantis.

Alinhou-se à tutela existencial da pessoa o paradigma do direito civil constitucional; contudo, a análise evidenciou os limites que esse paradigma enfrenta na atualidade relacionados as dificuldades de ampliação de titularidades, em especial do direito fundamental a moradia, em face da persistente carência de habitação destinada as pessoas de baixa renda no Brasil.

Paralelamente a essa questão, a análise evidenciou que a produção de moradia no Brasil observa ao longo da história, e mesmo nos dias atuais, um compromisso mais estreito com variáveis mercantis em detrimento do escopo de políticas públicas. Resulta dessa constatação a implicação entre o direito a moradia e a ordenação do mercado, o que coloca em evidência a redução do Estado de Direito as normas de direito privado. Consequentemente, o acesso à moradia fica sujeito à logica da concorrência no mercado e aos processos de financeirização.

Em face desse contexto, o alcance da normatividade do direito real de laje assume caráter exemplar ao permitir evidenciar a oscilação paradigmática nos fundamentos do direito civil na atualidade. Embora o direito real de laje, dada a realidade de dificuldades de acesso a moradia no Brasil, esteja desenhado para ampliar oportunidades de moradia entre pessoas de baixa renda, ele pode servir para ampliar formas de financeirização, em detrimento do propósito de assegurar vida digna. Permanece a retórica idealista de proteção da pessoa, enquanto no nível pragmático o direito civil procura realinhar-se subalternamente aos interesses de ganhos nos mercados financeiros. Mas isso não deve estranhar; para lembrar Roberto Schwarz, também no direito civil, o direito das coisas, de algum modo, desde o advento da República, parece estar fora do lugar.

\section{Referências bibliográficas}

ALONSO, Raquel Rodríguez; PINO, Mario Espinoza. De la especulación al derecho a la vivienda. Más allá de las contradicciones del modelo inmobiliario español. Madrid: Editorial Traficantes de Sueños, 2017. 
ARANTES, Pedro Fiori. Arquitetura nova - Sérgio Ferro, Flávio Império e Rodrigo Lefèvre, de Artigas aos mutirões. São Paulo: Editora 34, 2002.

AULER, Mariana Marques. Tradição, planejamento estratégico e reforma urbana no plano diretor de Curitiba: uma análise das interseções entre direito e política na cidade. Dissertação de Mestrado, Programa de pós-graduação em direito da UFPR, Curitiba, 2017.

BOBBIO, Norberto. Jusnaturalismo e positivismo jurídico. São Paulo: Editora Unesp, 2016.

CHENAIS, François. Finance capital today. Boston: Brill Acedemic Pub., 2016.

DARDOT, Pierre. LAVAL, Christian. A nova razão do mundo -ensaio sobre a sociedade neoliberal. São Paulo: Boitempo Editoral, 2016.

FACHIN, Luiz Edson. Repensando fundamentos do Direito Civil brasileiro contemporâneo. Rio de Janeiro: Editora Renovar, 2000.

FARIAS, Cristiano Chaves; EL DEBS, Martha; DIAS, Wagner Inácio. Direito de laje - do puxadinho à digna moradia. 2. ${ }^{a}$ ed., Salvador: Editora Juspodivm, 2018.

FIX, Mariana; PAULANI, Leda Maria. Considerações teóricas sobre a terá como puro ativo financeiro e o processo de financeirização. Revista de Economia Política. São Paulo, vol. 39 , n. 4 (157), outubro-dezembro de 2019, p. 638-657.

FOUCAULT, Michel. Nascimento da biopolítica. São Paulo: Martins Fontes, 2008.

HAYEK, Friedrich. Direito, legislação e liberdade - uma nova formulação dos princípios liberais de economia e justiça. São Paulo: Editora Visão, 1985, v. 02.

HEGEL, G.W.F. El sistema de la Eticidad. Madrid: Editora Nacional, 1982.

. Princípios da filosofia do direito. São Paulo: Martins Fontes, 2003.

LEAL, Fernando. Seis objeções ao direito civil constitucional. Direitos Fundamentais \& Justiça. Porto Alegre: HS Editora/PUCRS, ano 9, n. ${ }^{\circ}$ 33, p. 123-165, outubro/dezembro de 2015.

LIMA, Frederico Henrique Viegas de. Direito de laje: uma visão da catedral. Revista dos Tribunais. São Paulo, vol. 82, Janeiro-Junho de 2017, p. 251-280.

LOBO, Paulo. Direito civil - Parte Geral. 4. ${ }^{a}$ ed. São Paulo: Editora Saraiva, 2013.

. Direito Civil - Coisas. 2. ${ }^{\mathrm{a}}$ ed. São Paulo: Editora Saraiva, 2017.

PERLIGIERI, Pietro. Perfis do direito civil - Introdução ao direito civil constitucional. Rio de Janeiro: Editora Renovar, 1999. 
2008.

O direito civil na legalidade constitucional. Rio de Janeiro: Editora Renovar,

RIZZARDO, Arnaldo. O direito real de laje. Revista dos Tribunais. São Paulo, vol. 986, dezembro de 2017, p. 263-275.

RODOTÀ, Stefano. La vita e le regole - Tra diritto e non diritto. Milão: Feltrinelli Edittore, 2012.

RODRIGUES, Daniela Rosário. O direito à propriedade titulada por meio da regularização fundiária. In NALINI, José Renato; LEVY, Wilson (Coord.). Regularização Fundiária. 2. ${ }^{a}$ ed. Rio de Janeiro, Editora Forense, 2013, p. 25-47.

RODRIGUES JR., Otávio Luiz. Direito civil contemporâneo - Estatuto epistemológico, Constituição e direitos fundamentais, Rio de Janeiro: Editora Forense Universitária, 2019.

ROLNIK, Raquel. Guerra dos lugares - a colonização da terra e da moradia na era das finanças. São Paulo: Boitempo Editorial, 2015.

SCHMITT, Carl. O guardião da Constituição. Belo Horizonte: Editora Del Rey, 2007.

SPINOZA, B. Ética. São Paulo: Autêntica Editora, 2015.

TARTUCE, Flávio. A lei da regularização fundiária (Lei 13.465/2017): análise inicial de suas principais repercussões para o direito de propriedade. Pensar - Revista de Ciência Jurídicas. Fortaleza, v. 23, n. 3, p. 1-23, jul./set. 2018. 